\title{
سياسات مكافحة الفساد في إطار العدالة الانتقالية في تونس
}

\section{Fighting Corruption within the Framework of Transitional Justice in Tunisia}

تُسلّط هذه الدراسة الضوء على الربط القانونسي الذي حصل في تونس بين العدالة الانتقالية وسياسات مكافحة الفساد من أجل تقييم هذه السياسات، وتتتبّع آثار ذلك في في عملية التوات التحوّل

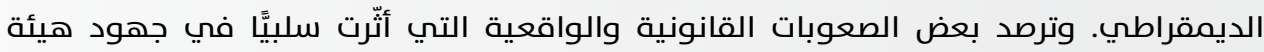

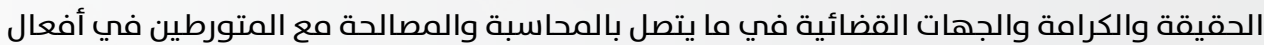

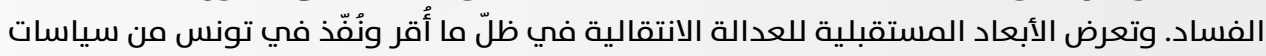

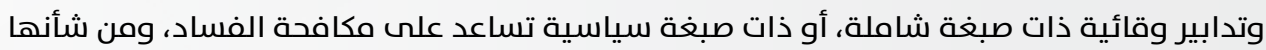

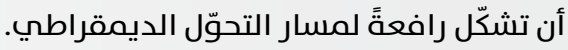

كلمات مفتاحية: مكافحة الفساد، عدالة انتقالية، محاسبة، مصالحة، وقاية، تحوّل ديمقراطي.

This research examines the connection between transitional justice and combating corruption in Tunisia. The study highlights some of the legal and practical impediments to the work of the Truth and Dignity Commission, which prevent it from fulfilling its objectives related to determining the accountability and reconciliation. This research also investigates perspectives of preventing corruption related to democratic transition in Tunisia.

Keywords: Combating Corruption, Transnational Justice, Accountability, Reconciliation Preventing Corruption, Democratic Transition. 


\section{مقدمة}

أخذ الاهتمام بظاهرة الفساد المالي منحى غير مسبوق في تونس بعد ثورة الحرية والكرامة؛ ثورة 14 جانفي 2011.

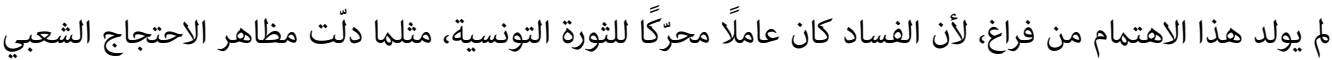

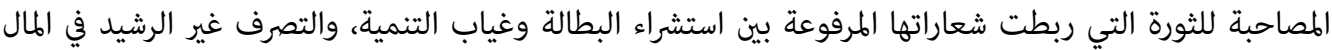

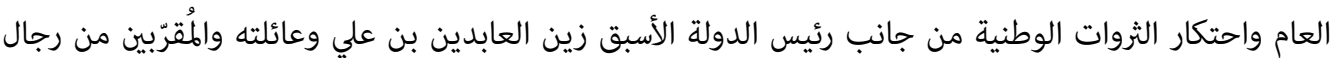
الأعمال (1).

اتخذ التعامل مع ظاهرة الفساد بعد الثورة سبيلين: يتوغل أوّلهما في الماضي بحثًا عن أفعال الفساد التي ارتكبت من

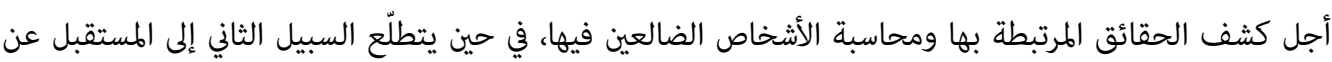
طريق إصلاح مؤسسات الدولة ووضع ما يلزم من نصوص وآليات تضمن محاصرة الفساد وانحساره. وسنّت الدولة

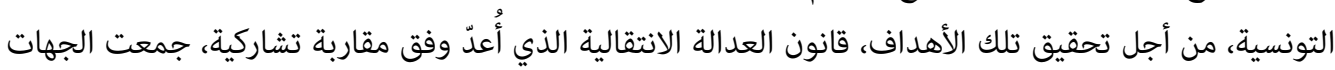

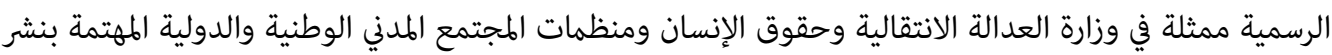

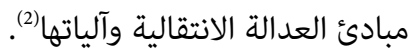

تبنّى قانون العدالة الانتقالية تعريفًا واسعًا للعدالة الانتقالية مقتبسًا من المعايير الدولية، وغير مقتصر على العدالة

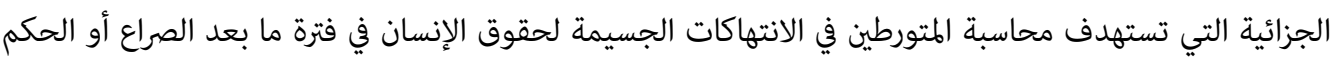

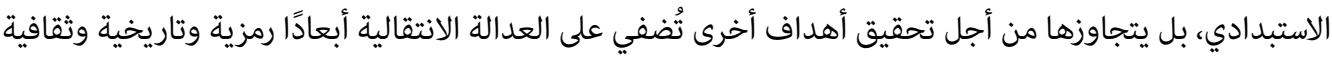

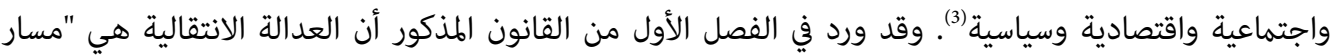
متكامل من الآليات والوسائل المعتمدة لفهم ومعالجة ماضي انتهاكات حقوق الإنسان بكشف حقيقتها ومحاسبة المسؤولين عنها وجبر ضرر الضحايا وردّ الاعتبار لهم بما يحقق المصالحة الوطنية ويحفظ الذاكرة الجماعية ويوثقها

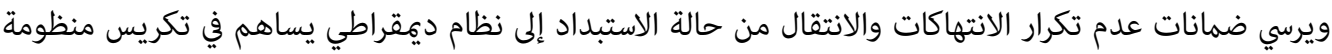
حقوق الإنسان"(4). (2) (2)

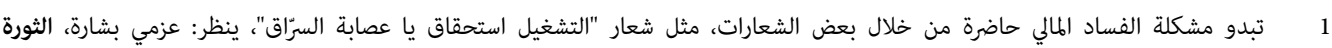

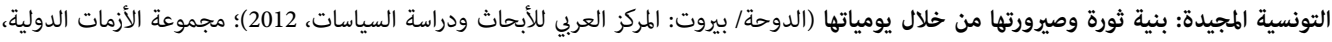

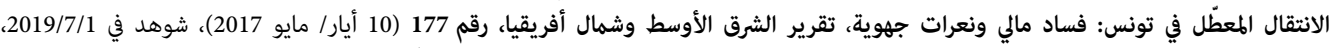

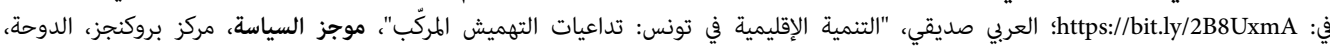

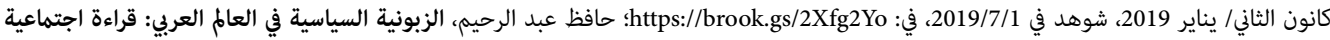

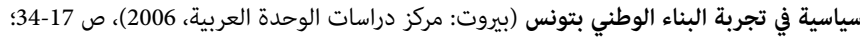
Béatrice Hibou, La force de l'obéissance: Economie politique de la répression en Tunisie (Paris: La découverte, 2006).

2

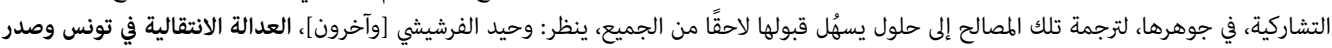

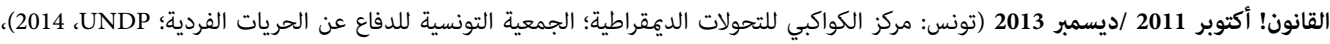

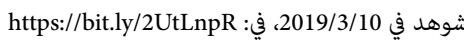

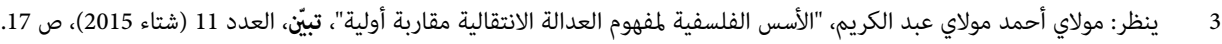

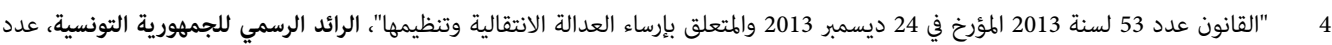

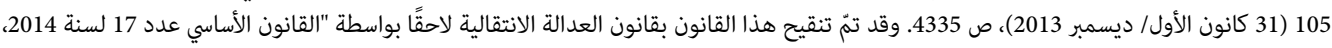

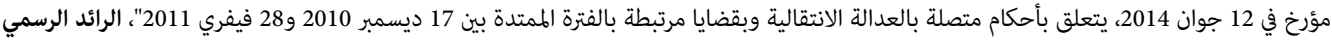
للجمهورية التونسية، عدد 48 (17 حزيران/ يونيو 2014)، ص 1619. 
تضمّن قانون العدالة الانتقالية إضافتين مهمتين تتمثل أولاهما في تحميل العدالة الانتقالية عبء مكافحة الفساد

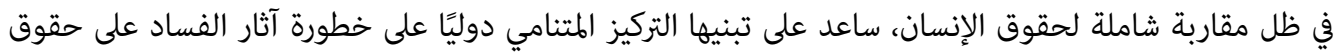
الإنسان السياسية والاقتصادية والاجتماعية (5. وينصرف المفهوم القانوني للفساد في سياق العدالة الانتقالية الجزائية

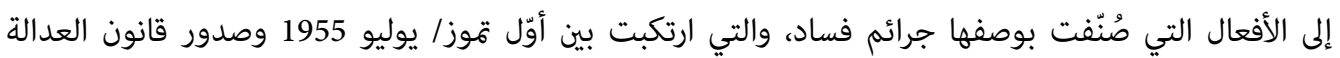
الانتقالية في 24 كانون الأول/ ديسمبر 2013؛ ما يعني السعي لتحديد المسؤوليات عن جرائم الفساد المالي والاعتداء على المال العام المرتكبة من الأشخاص المتورطين، سواء كانوا راشين أو مرتشين، فاعلين أصليين أو شركاء، مستغلين

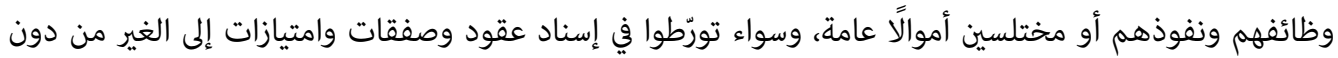

وجه حق، أو تربّحوا لفائدتهم الشخصية أو لفائدة أقاربهم أو أحزابهم ومنظمهاتهم ومؤسنساتهم الاقتصادية (6). أمّا الإضافة الثانية المهمة، فتتمثل في تحميل العدالة الانتقالية هدف المساهمة في إرساء ضمانات "الانتقال من

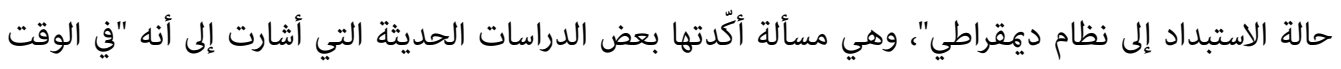

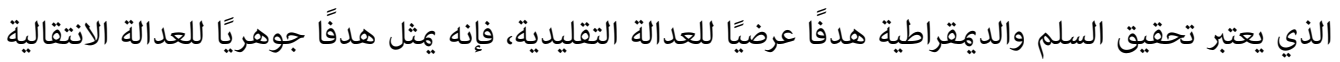
يجب تحقيقهما"، ولذلك "أصبح لزامًا أن تكون العدالة الانتقالية - بوصفها آلية لمعالجة تركة غياب الديمقراطية في الممارسات السلطوية - آلية للمطالبة بالديمقراطية وتحقيقها، لكون الديمقراطية العلاج الوحيد القادر على منع تكرار الأخطاء التي تريد هذه العدالة الانتقالية أن تُعالجه بإجراءاتها المؤقتة"(7). يُفضي الربط بين مكافحة الفساد والانتقال الديمقراطي إلى تصور خاص لكافحة الفساد يتميّز بالانزياح عن الحلول التقليدية التي يطغى عليها البعد الجزائي، والتي تعتمدها الدولة في الأوضاع العادية لمحاصرة الفساد (8). وتمثّل العدالة الانتقالية بما يمكن أن تحققه من مكاسب مستقبلية، مثل استرجاع بعض الأموال المنهوبة وتحقيق المصالحة

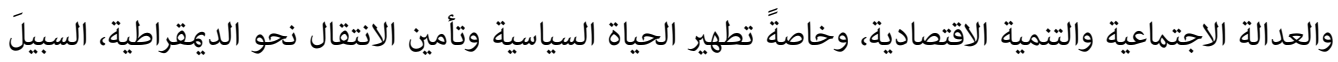

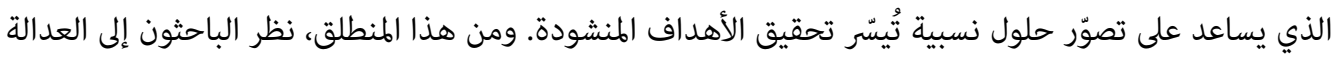
الانتقالية بوصفها حلقة من الحلقات الأساسية للإصلاح السياسي الذي يهدف إلى بناء نظام ديمقراطي قائم على دولة القانون والعدالة بكعناها الشامل (9).

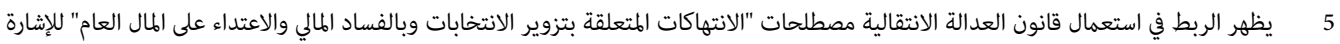

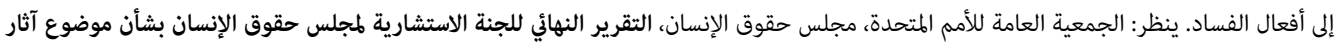

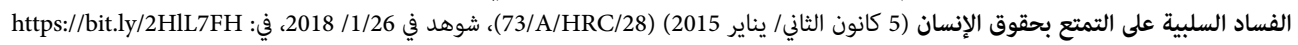
6 م 6 7 روكولاي عبد الكريم، ص 18؛ ينظر أيضًا: نهى أبو الدهب، "سياسات العدالة الانتقالية في السياقات السلطوية: الحالة المصرية"، موجز السياسة، مركز

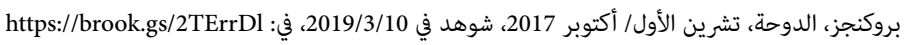

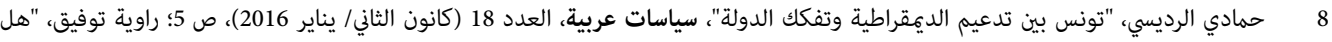

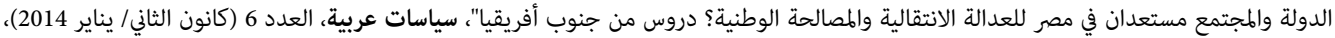

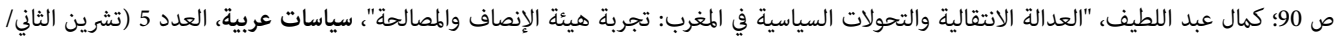

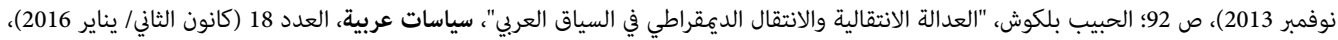

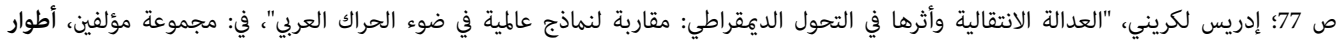

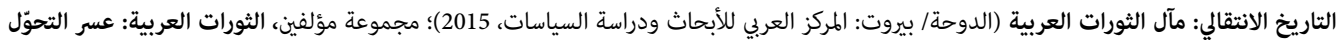

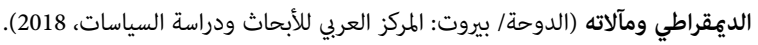

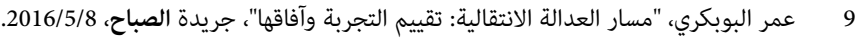


يقتضي تحيص الربط الذي حصل بين مكافحة الفساد والعدالة الانتقالية طرح السؤال المحوري: ما مدى مساهمة خيار مكافحة الفساد بمنطق العدالة الانتقالية وآلياتها في خدمة مسار الانتقال الديمقراطي في تونس؟ تستوجب الإجابة عن هذا السؤال التعمّق في دراسة الهدفين المحورين اللذين يسندان خيار إدماج مكافحة الفساد في إطار مسار العدالة الانتقالية، المتمثلين في المساعدة على محاسبة مرتكبي أفعال الفساد وتحقيق المصالحة الوطنية وضمان الشروع في إصلاح مؤسسات الدولة بما يضمن محاصرة الفساد. وسيتم ذلك، من خلال عرض معالجة

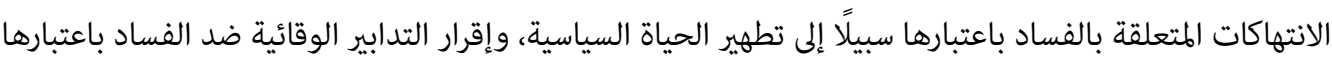
سبيلًا إلى ترسيخ الخيار الديمقراطي.

\section{أولًا: معالجة الانتهاكات المتعلقة بالفساد سبيلًا إله تطهير الحياة السياسية}

تُبنى العدالة الجزائية التقليدية على تتبع المجرمين من أجل محاكمتهم، وإصدار العقوبات المناسبة وإنفاذها بقطع

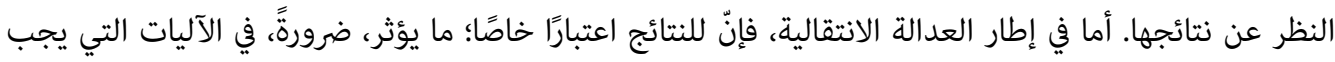

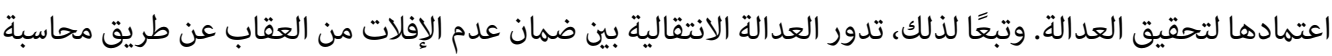
المتورطين في جرائم الفساد وتحديد المسؤوليات، والتأسيس للمستقبل وطيّ ملف الماضي عن طريق المصالحة.

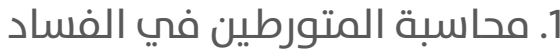

انطلقت في تونس محاسبة المتورطين في جرائم الفساد المرتكبة خلال فترة الاستبداد مباشرة بعد ثورة الحرية والكرامة، في وضع اتّسم، بعد هروب رئيس الدولة الأسبق زين العابدين بن علي، في 14 كانون الثاني/ يناير 2011، بتداخل الصلاحيات بين السلطات نتيجة تعليق العمل بدستور عام 1959 وغلبة المنطق الثوري على التقيّد بالإجراءات

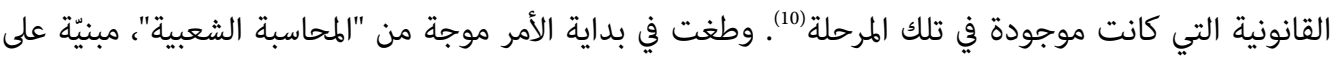
شُبهات فساد، وظهرت من خلال رفع شعار "ديقاج" أو "ارحل"، في وجه عدد من الوزراء وكبار موظفي الدولة

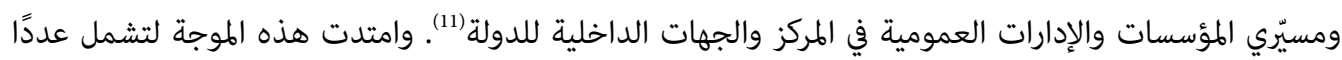
كبيرً من رجال الأعمال الذين كانت لهم معاملات اقتصادية داخل الدولة وخارجها، والذين حصلوا في ظل النظام السابق على امتيازات بطرائق غير قانونية

بدأت الأمور تنتظم قانونيًا في مرحلة لاحقة مع صدور مجموعة من القوانين والقرارات الهادفة إلى محاسبة المتورّطين

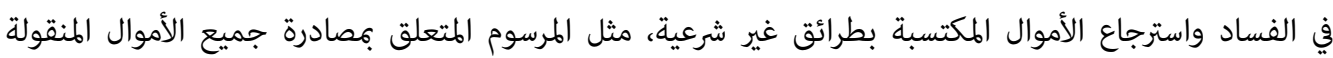
10

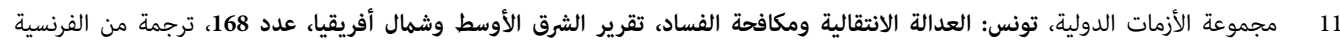

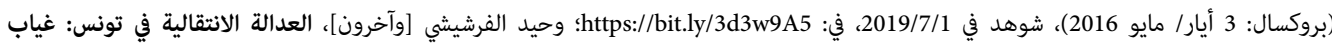

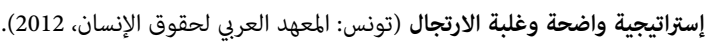
12 12 
والعقارية والحقوق المكتسبة، بعد 7 تشرين الثاني/ نوفمبر 1987، الراجعة إلى مجموعة من الأشخاص، على رأسهم بن علي وزوجته (13).

اتسمت محاولة كشف الحقائق وتحديد المسؤوليات منذ عام 2011 باللجوء إلى لجان مستقلة؛ فكان أول قرار، بعد إنشاء لجنة التقصي في أحداث العنف والقتل التي حصلت إبّان الثورة، إنشاء لجنة للتقصّي في أفعال الفساد والرشوة

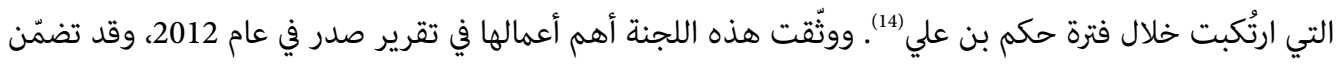

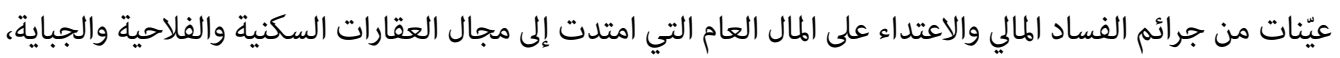

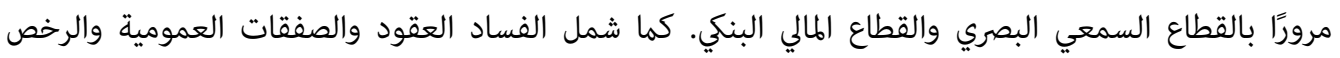
ومختلف القرارات الإدارية(15). وخلص التقرير إلى أنّ البلاد التونسية كانت تحت حكم الرئيس الأسبق "ضحية

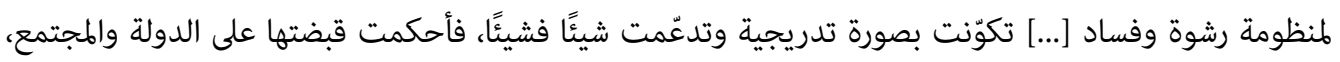

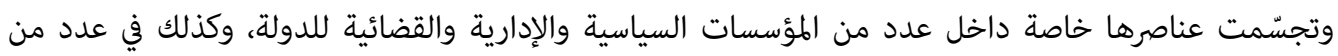
الجماعات العمومية والمؤسسات والمنشآت العمومية. كما شملت منظمات سياسية، وعلى رأسها التجمع الدستوري الديمقراطي، وأخرى اجتماعية، وعددًا من وسائل الإعلام والاتصال"(16.".

أكدت هيئة الحقيقة والكرامة التي أُنشئت في عام 2014، واستمرت في العمل مدة خمسة أعوام، المعطيات التي توصّلت إليها لجنة التقصي في أفعال الفساد والرشوة، فقد رصد تقريرها النهائي الصادر في أواخر عام 2018 عدد فئد التجاوزات المرتكبة في المجال العقاري والمالي والبنكي والجباية، وسوء التصرف في الثروات الطبيعية والمؤسسات العمومية وبعض أجهزة الدولة مثل أجهزة الجمارك (17).

ساهمت التقارير المتعددة في فهم طبيعة الفساد الذي ضرب البلاد التونسية خلال فترة الاستبداد، وهو صنف خطر

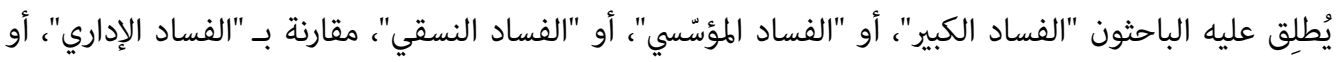

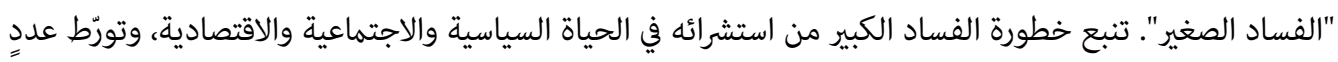
مهم من كبار المسؤولين والطوظفين في الدولة ورجال الأعمال (18.)

كان من المفترض أن يدفع انكشافُ الفساد وشبكاته الأجهزة القضائية إلى القيام بدور حاسم في المحاسبة؛ باعتبار أن

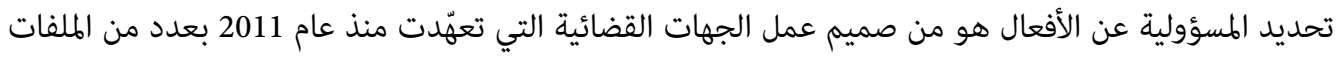

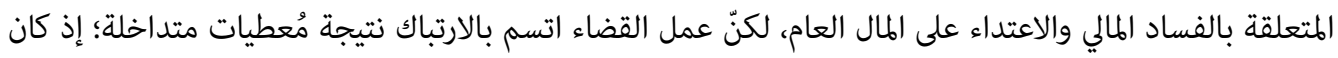

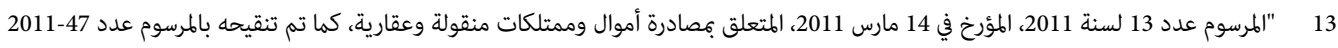

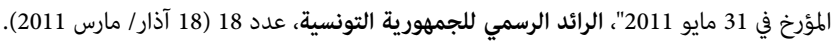

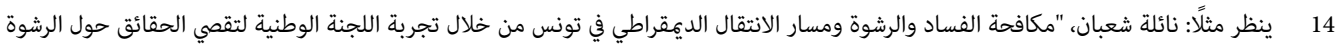

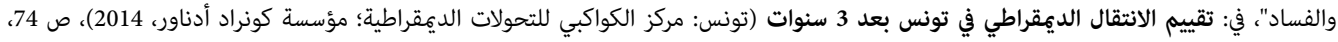
شوهد في 2020/6/13، في: شوttps://bit.ly/3fjUjrO 15 الجمهورية التونسية، الهيئة الوطنية لككافحة الفساد، تقرير اللجنة الوطنية لتقصي الحقائق حول الرشوة والفساد (تونس: 2012)، ص 1. 16

17 الجمهورية التونسية، هيئة الحقيقة والكرامة، التقرير الختامي الشامل (تونس: كانون الأول/ ديسمبر 2018)، شوهد في 2019/4/25، في: https://bit.ly/37qv1pf 18 الجمعية العامة للأمم المتحدة، مجلس حقوق الإنسان، التقرير النهائي للجنة الاستشارية لمجلس حقوق الإنسان. 
القضاء يشكو، بصفة عامة، من فقدان الثقة بسبب توظيف النظام السابق له قبل الثورة، ونتيجةً للتدخل المُفرط في

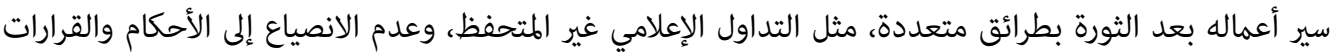
القضائية، والتهجّم على القضاة واقتحام أماكن عملهم من المتقاضين بهدف التأثير في التحقيقات الجارية، وأحيانًا

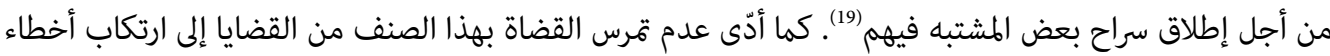
إجرائية كان لها آثار سلبية في مجال استرجاع الأموال المنهوبة في الخارج على وجه الخصوص (20). تجلّى الارتباك في مستوى عمل القضاء بصنفيه العدلي والإداري، فقد تعهّد جهاز القضاء الإداري بالنظر في عدد من القضايا، مثل الطعون المتعلقة ببطلان بعض الصفقات العمومية أو القرارات المتعلقة بالجباية أو بمصادرة أموال

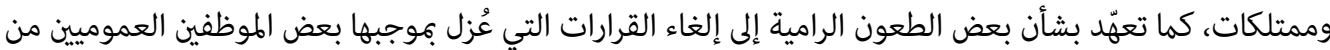
أجل شبهات فساد، مثل بعض القضاة الذين أعفتهم السلطة التنفيذية مباشرة بعد الثورة(21). أما في مستوى القضاء العدلي - الذي كان متعهدًا بالنظر أساسًا في القضايا ذات الصبغة الجزائية المتعلقة بالأشخاص المتهمين بارتكاب أفعال فساد - فاتسم عمله بالبطء الشديد نتيجة كثرة املفات، وبقي عاجزًا عن إصدار الأحكام في القضايا المرفوعة إليه. وحاول قانون العدالة الانتقالية إحداث نقلة نحو محاسبة منضبطة من حيث الوسائل والأهداف بأنْ حصر مهمة المحاسبة في ملفات العدالة الانتقالية - سواء اتصلت بانتهاكات حقوق الإنسان أو بأفعال الفساد - بين أيدي هيئة الحقيقة والكرامة، وهي جهة غير قضائية تتولّى البحث والتقصي، وإحالة الملفات التهات التي كوّنتها

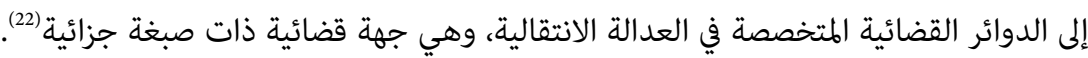

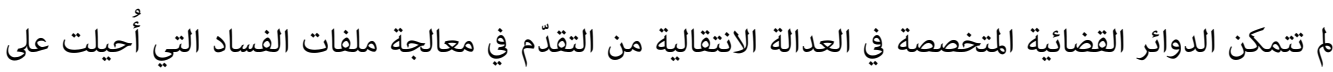

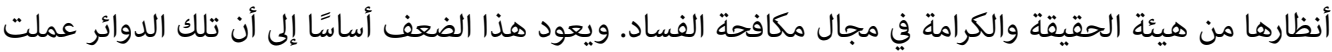

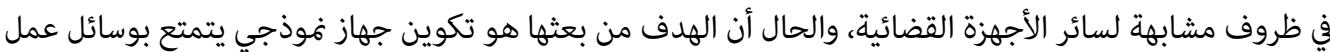
عصرية تُّكّن من تجاوز عوائق تقليدية تتّصل بإثبات الوقائع والأفعال في جرائم الفساد. الخلاصة أن أجهزة الدولة الرسمية، وعلى رأسها هيئة الحقيقة والكرامة، مل تتمكّن من إنجاز مهمة البحث والتقصي

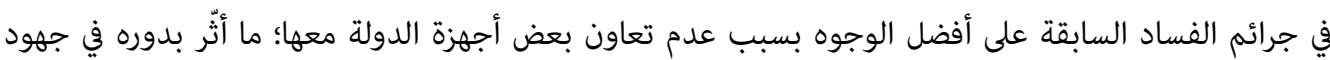

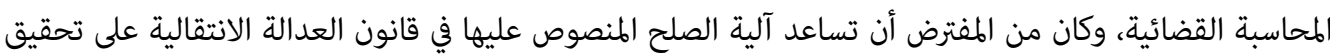
المصالحة وتجاوز العراقيل التي تُعظّل عمل القضاء. 13/6/2020, at: https://bit.ly/2XVon7b

21 مروان 2 الدروناسي، "المراسيم المتخذة في المرحلة الانتقالية: قراءة على ضوء قواعد الشرعية الدستورية ومقتضيات المشروعية الثورية"، في: أحمد السوسي

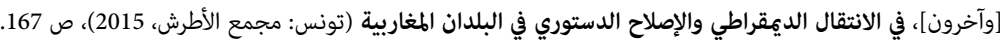

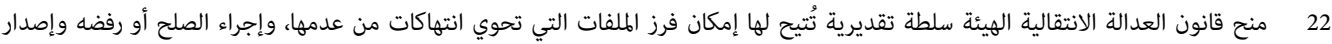

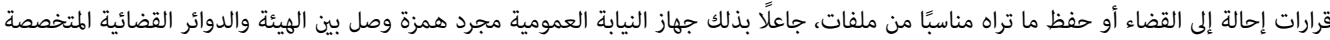




\section{2. المصالحة مع المتورطين في الفساد}

تَثّل "المصالحة" هدفًا رئيسًا من أهداف العدالة الانتقالية التي تسعى لتجاوز تركة الماضي والتأسيس لمستقبل يخلو من الاستبداد والفساد في ممارسة السلطة وفي المجتمع على حدّ سواء. وقد عرّف أحد الباحثين في هذا السياق المصالحة بأنها "الجهود الرامية إلى إرساء السلام والثقة بين المواطنين وبين الخصوم القُدامى"(23).

تجد المصالحة بما تعنيه من طيٍّ لصفحة الماضي أرضية مواتية لها في مجال مكافحة الفساد لعدة اعتبارات، أهمها

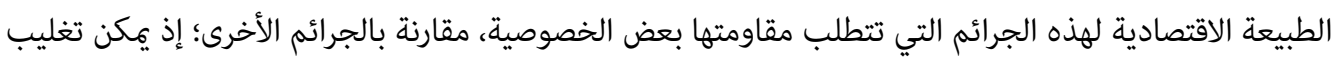

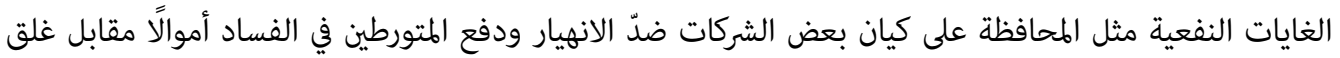

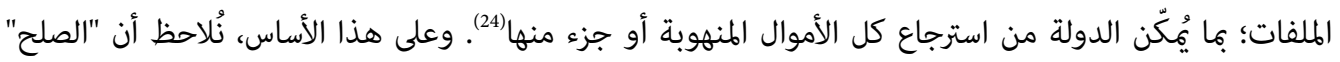
مع المتورّطين في الفساد، وخاصةً الفاعلين الاقتصاديين، مثل الشركات على وجه الذهاع الخصوص، يمثل اليوم إحدى الآليات الرئيسة المعتمدة في القوانين الحديثة لكافحة الفساد (25).

مل تعمل آلية الصلح في السياق التونسي بالكيفية التي تحقق المصالحة وتضمن الوصول إلى أهدافها. فمن جهة أولى، مل يشكل السلاح الجزائي أداة ضاغطة لإنجاز الصلح نتيجة ضعف المحاسبة القضائية التي عزّزت احتمالات إفلات

$$
\text { المتورطين في الفساد من العقاب. }
$$

من جهة ثانية، تأرجحت آلية الصلح، التي اعتمدت عليها هيئة الحقيقة والكرامة في مجال الانتهاكات المتعلقة بالفساد الهالي والاعتداء على المال العام، بين فرضية "انقضاء الدعوى العمومية أو إيقاف المحاكمة أو إيقاف تنفيذ العقوبة" وفرضية نقض الصلح بعد حصوله والشروع في تنفيذه(26). وكان من المفترض أن يدفع تعدّد الاحتمالات نحو تغليب آلية الصلح، لكنه انتهى إلى إرسال رسالة إلى المعنيّين مفادها أن إبرام الصلح مع إمكان نقضه إنه لا يشكل حلَّاً نهائَّا. من جهة ثالثة، سعت السلطة السياسية المنبثقة من الانتخابات التشريعية والرئاسية عام 2014 إلى تعطيل أعمال هيئة الحقيقة والكرامة بطريقة قانونية وأخرى واقعية. فمن الناحية القانونية صادق مجلس نواب الشعب في أواخر عام 2017 على مشروع قانون يتعلق بالمصالحة في المجال الإداري، أدى إلى إعفاء الموظفين العموميين المتورطين في

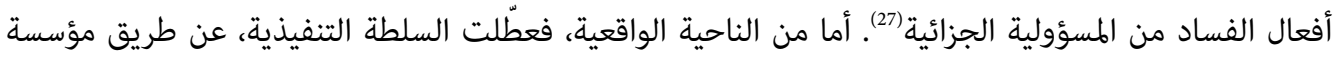

$$
23 \text { مولاي عبد الكريم، م } 30 .
$$

25 Akila Taleb, "Les procédures de Guilty Plea: Plaidoyer pour le développement des formes de justice négociée au sein des procédures pénales modernes," Revue internationale de droit pénal, vol. 83, no.1 (2012), p. 89.

26 2 الفصل 45، فقرة 2 من قانون العدالة الانتقالية، الرائد الرسمي للجمهورية التونسية، عدد 48.

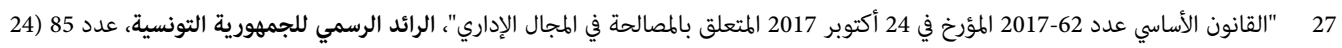

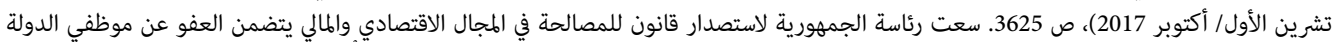

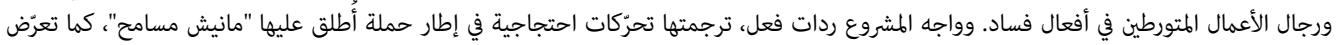

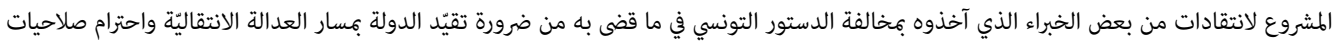

هيئة الحقيقة والكرامة، ينظر:

Pablo de Greiff, "Analyse du Projet de loi organique relative aux procédures spéciales concernant la réconciliation dans les domaines économique et financier," Rapporteur spécial sur la promotion de la vérité, de la justice, de la réparation et des garanties de non-répétition, accessed on 13/6/2020, at: https://bit.ly/2tUKdb1 
المكلف العام بنزاعات الدولة، إجراءات الصلح مع رجال الأعمال المتورطين في الفساد التي تشرف عليها هيئة الحقيقة والكرامة؛ ما أدّى إلى تمتعهم بعفو واقعي، ويعني هذا الأمر تجاوزًا للدستور وقانون العدالة الانتقالية وتكريسًا للإفلات من المحاسبة وعدم إرجاع الأموال المنهوبة (28).

يكن القول إن العدالة الانتقالية المتصلة بمكافحة الفساد تأرجحت في مجال المصالحة بين توجّه يميل إلى كشف الحقائق والمحاسبة واسترجاع الأموال المنهوبة من ناحية، وتوجّه يُعلي الرغبة في الصلح الذي يطوي صفحة الماضي من من من دون محاسبة، ومن دون إرجاع تلك الأموال من ناحية أخرى. ففي حين يرى البعض ونه أن المصالحة من دون محاسبة

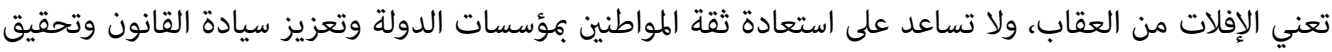

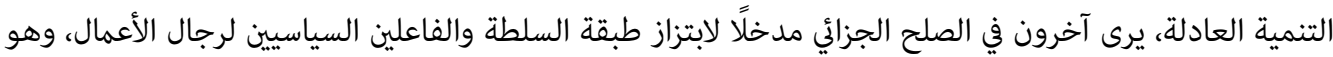
ما لا يضمن المصلحة العامة الكامنة فيه، ولا يساعد على إيجاد الحلول الضرورية لمشكلات المواطنين الاجتماعية والاقتصادية (29).

الحقيقة أن العدالة الانتقالية المتصلة بكافحة الفساد ارتبطت في تونس بالإجراءات الثورية التي اتُّخذت، بعد قيام الثورة، ضد رجال الأعمال الذين تعلّقت بهم شُبهات أو قضايا فساد؛ ما أعطى انطباعًا مفاده أن المسار تغلب الب عليه الصبغة الانتقامية، ولا يفتح صفحة جديدة نحو المستقبل. ساهم عدم إنجاز المصالحة الاقتصادية، طِبقًا لآليات العدالة الانتقالية، بالإبقاء على تداول حجم من الأموال مصدرها الفساد في الحياة العامة؛ ذلك أن بقاء رجال الأعمال تحت طائلة الابتزاز السياسي، يدفعهم إلى البحث عن الحماية

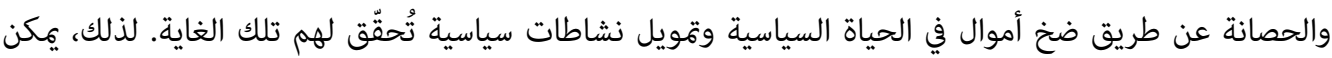
القول إن المصالحة الاقتصادية أضحت ضروريةً من أجل تطهير الحياة السياسية من الهال الفاسد ودعمم مسار الانتقال الديمقراطي. غير أن ذلك يبقى مطلبًا صعب المنال، ما دام مل يقع التركيز على الغايات الجوهرية للعدالة الانتقالية

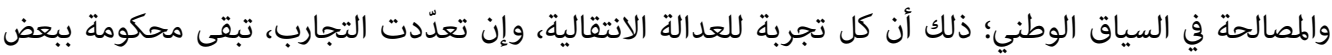

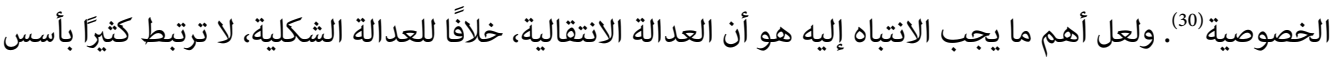
ثابتة، أو سوابق جامدة، "وإنّا منطلقها هو حالة وضع قائم بأبعاده القانونية والسياسية والإنسانية، حيث يعرف

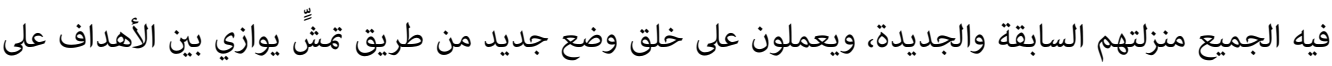

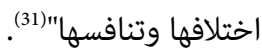

قد تبدو المصالحة الاقتصادية في ظاهرها مؤشرًا دالًّ على ضعف الدولة وعجزها عن محاسبة الفاسدين، وهو رأي

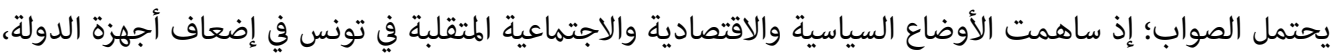
ما في ذلك هيئة الحقيقة والكرامة، ما جعل الدولة عاجزة عن أن تردع الفساد، سواء بالترهيب أو بسياسات المهادنة

28 وحيد الفرشيشي، "هل تلتزم الدولة بتنفيذ نظام العدالة الانتقالية؟"، ورقة مقدمة في الملتقى العلمي "الدستور التونسي على محك السياسة"، جمعية البحوث في الانتقال الديمقراطي، تونس،

29

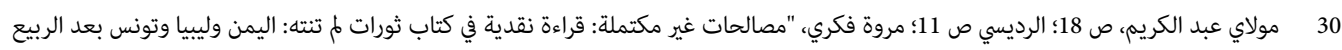

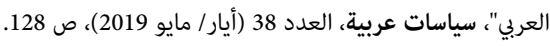
20 مولاي عبد الكريم، ص 231 
والترغيب. غير أن المصالحة الاقتصادية قد تُساعد اليوم الدولة على استعادة عافيتها؛ إذ تُمّكنها من التخلص من تركة

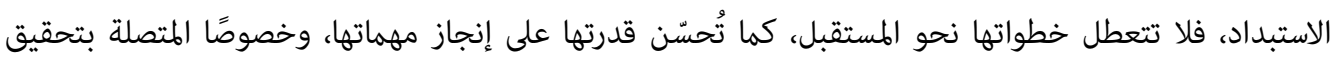
الانتعاش الاقتصادي بصفته شرظًا رئيسًا لنشأة دولة قوية تتزاوج فيها الديمقراطية بالأمن والحرية والرفاه، وذلك شرط طكافحة الفساد مستقبلًا (32).

\section{ثانيًا: الوقاية من الفساد سبيلًا إله ترسيخ الديمقراطية}

لا تتوقف العدالة الانتقالية المتصلة بمكافحة الفساد عند الماضي، بل تتطلّع إلى المستقبل بواسطة عملية إصلاحية شاملة ذات صبغة وقائية تسعى لمنع تكرار الأفعال التي ارتُكبت سابقًا. ومن خصائص تجربة العدالة الانتقالية

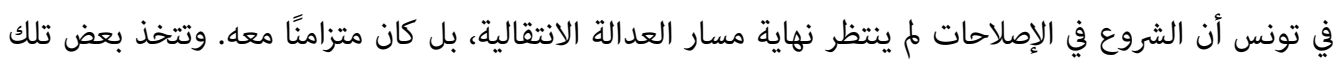
الإصلاحات الهادفة إلى الوقاية من الفساد صبغة شاملة، في حين تكتسي بعض الإصلاحات الأخرى صبغة سياسية.

\section{1. دور الإصلاحات الشاملة في الوقاية من الفساد}

تتجه اليوم مختلف دول العالم نحو استنباط حلول لكافحة الفساد تتلاءم مع تطوّر هذه الظاهرة المُعقّدة، وهو تطور مرتبط - من ناحية - بما تشهده الدول من تحوّلات في مستوى هياكلها ومؤسساتها والوظائف الموكلة إليها،

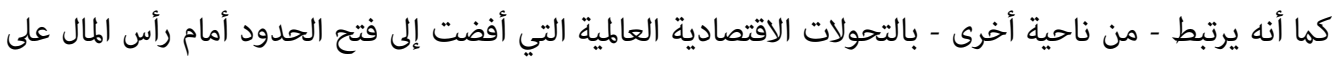
نحو غير مسبوق، وسمحت بإمكانات للاستثمار واكتساب الملكية وتحويل الأموال الحر عبر الدول بواسطة البنوك التقليدية، أو باعتماد تكنولوجيات الاتصال الحديثة، وما تنفتح عليه هذه العولة من عولة للفساد والجريمة، بصفة عامة، من حيث الأطراف المتدخلة ووسائل ارتكابها أو إخفاء آثارها (33).

تبعًا لذلك، مل تعُد مكافحة الفساد مكافحة للرشوة في شكلها التقليدي، بل أصبحت الدول تيل إلى محاصرة الفساد

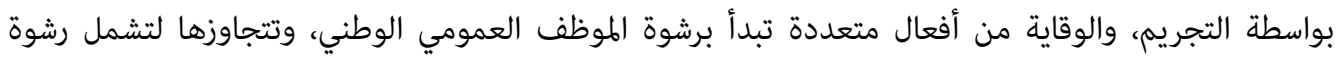

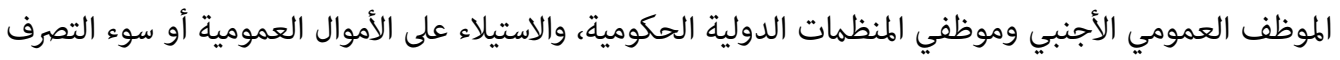

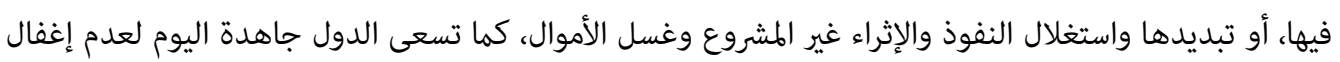
الرشوة التي تضرب القطاع الخاص وتتورّط فيها مؤسسات وشركات وطنية ومتعددة الجنسيات؛ ما يؤثر في إمكانات المنافسة الحرة والنزيهة (34).

بعد الثورة، بانت في تونس الحاجة إلى إصلاحات تشريعية موجّهة لمكافحة الفساد، بحكم أن الثورة كانت فرصة

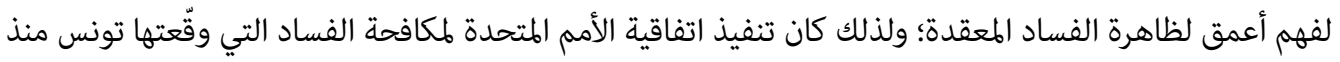

32

33 Adnen Nouioua, "La lutte contre la corruption et le droit international," Thèse de doctorat en droit public, Université de Tunis Al Manar, Faculté de droit et des sciences politiques, Tunis, 2018; Mireille Delmas-Marty, Le relatif et l'universel: Les forces imaginantes $d u$ droit (Paris: Editions du Seuil, 2004).

34 Philippe Janot, "Firmes Transnationales, Corruptions, États," Annuaire Français de Droit International, vol. vi (2005), p. 426. 
عام 2004، وصادقت عليها في عام 2008، من بين أوّل التدابير المتخذة بهدف تقييم مدى تلاؤم المنظومة القانونية مع تلك الاتفاقية وسَنّ النصوص الضرورية لمحاربة الفساد.

في السياق ذاته، تضمّن الدستور التونسي الصادر في 27 كانون الثاني/ يناير 2014 قواعد متصلة بمكافحة الفساد والحوكمة الرشيدة، مقتديًا في ذلك بالدساتير الحديثة التي سنّتها دول مرّت بمراحل انتقال ديمقراطي مهمة، مثل بعض

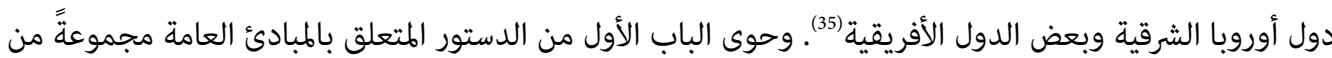
الالتزامات والتوجّهات العامة، مثل التزام الدولة بحسن التصرف في المال العمومي، وهو ما نصّ عليه بوضوح الفصل العاشر من الدستور حين أكد أن "تحرص الدولة على حُسن التصرّف في المال العمومي وتتخذ التدابير اللازمة لصرفه حسب أولويات الاقتصاد التونسي وتعمل على منع الفساد وكل ما من شأنه المساس بالسيادة الوطنية"(36). يمكن اعتبار دسترة مكافحة الفساد من أهم التدابير التي اتُخذذت في تونس؛ بالنظر إلى كون الدستور يعلو سائر

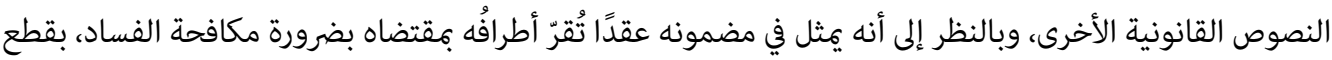
النظر عن اختلافاتهم الفكرية أو السياسية أو الحزبية. لكن الصعوبة تكمن في أن تطبيق بنود مكافحة الفساد يُصبح

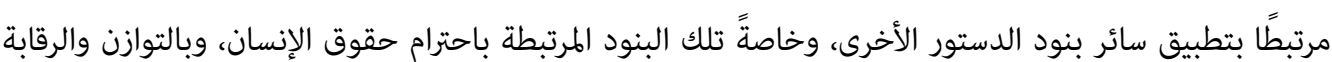
بين مختلف السلطات؛ ما يُكّن السلطة من أن تُحدّ السلطة، وهي مسائل لا يمكن أن تتحقق بالسرعة المطلوبة خلال الفترات الانتقالية؛ بالنظر إلى ثقل تركة الاستبداد وضعف الثقافة الدستورية في المجتمع (37). إضافة إلى الدستور، تحتوي المنظومة القانونية في تونس اليوم مجموعةً من النصوص الرادفة لمكافحة الفساد، مثل القانون المتعلق بإحداث القطب القضائي الاقتصادي والمالي، والقانون المتعلق بهيئة الحوكمة الرشيدة ومكافحة

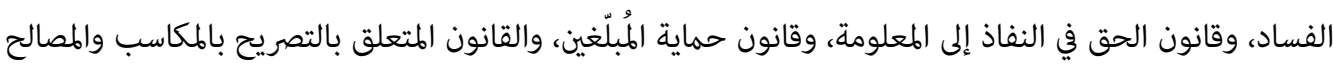
ومكافحة الإثراء غير المشروع وتضارب المصالح في القطاع العام (38). أما من الناحية المؤسساتية، فخُصّص الباب السادس من الدستور للهيئات الدستورية المستقلة، وهي هيئات تتولّى مهمات متعددة، مثل الإشراف على الانتخابات، أو حماية حقوق الإنسان، أو تعديل الإعلام السمعي البصري وحماية

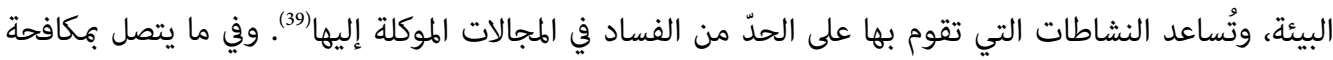
الفساد، نصّ الفصل 130 من الدستور التونسي على إحداث "هيئة الحوكمة الرشيدة ومكافحة الفساد"، وقد عُهد إليها أن تُساهم في "سياسات الحوكمة الرشيدة ومنع الفساد ومكافحته ومتابعة تنفيذها ونشر ثقافتها وتعزّز مبادئ

$$
35
$$

André Cabanis \& Michel Louis Martin, "De la dénonciation de la corruption à la recherche de la transparence dans le constitutionnalisme d'Afrique francophone," in: Mohamed Naceur Loued et al. (eds.), Transparence financière et réformes institutionnelles (Tunisie: Faculté des sciences juridiques, économiques et de gestion de Jendouba, 2008), pp. 69-77.

$$
36
$$

37 Michel Dobry, "Les voies incertaines de la transitologie: Choix stratégiques, séquences historiques, bifurcations et processus de path-dependence," Revue Française de science politique, vol. 50, no. 4-5 (2000), p. 585.

38 الهيئة الوطنية لكافحة الفساد، مجموعة النصوص القانونية المتعلقة بمكافحة الفساد، ط 3 (تونس: الشركة التونسية للنشر وتنمية فنون الرسم، 2019). 
الشفافية والنزاهة والمساءلة"، كما "تتولّى الهيئة رصد حالات الفساد في القطاعين العام والخاص، والتقصّي فيها، والتحقّق منها، وإحالتها على الجهات المعنية"(40).

تعتبر "هيئة الحوكمة الرشيدة ومكافحة الفساد" الهيكل الذي سيخلف "الهيئة الوطنية لمكافحة الفساد" التي بُعثت

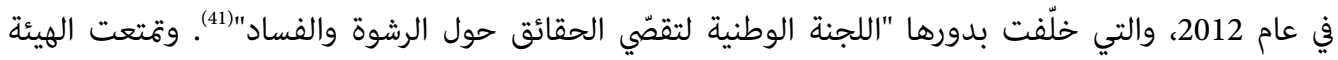

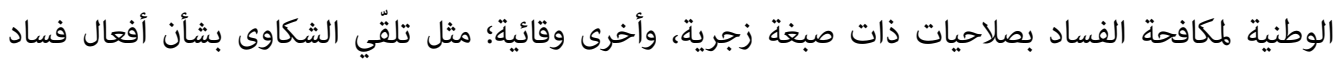
والتحقيق فيها وإحالتها إلى الجهات الإدارية والقضائية المختصّة، وجمع المعطيات والبيانات والإحصاءات، ونشر

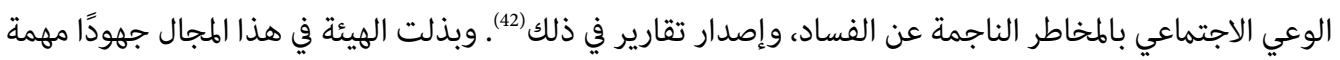
من أجل وضع بنية تحتية تشريعية ومؤسساتية ومجتمعية لكافحة الفساد، لكنها اصطدمت بصعوبات والفيات واقعية وقانونية تعود في الأساس إلى ضعف الصلاحيات الزجرية المسندة إلى الهيئة نفسها، فهي ليست من صنف الهيئات

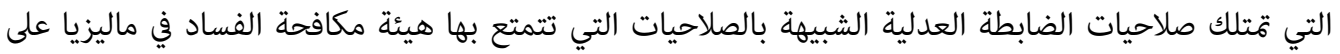
سبيل المثال، والتي تُكّنها من القبض على المشتبه فيهم والتحقيق معهم وحجز الوثائق والأدلّة، وهو ما ملم يُسمح

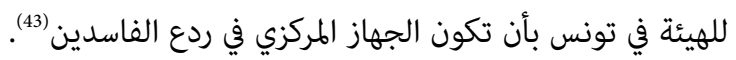

يبرز في هذا المجال الدور الوقائي الذي اضطلعت به هيئة الحقيقة والكرامة التي أسندَ إليها قانونُ العدالة الانتقالية مهمةَ البحث عن مواطن الخلل السابقة في تسيير الدولة، و"صياغة التوصيات والاقتراحات المتعلقة بالإصلاحات السياسية والاقتصادية والإدارية والأمنية والقضائية والإعلامية والتربوية والثقافية وغربلة الإدارة، وغيرها من التوصيات والاقتراحات التي تراها ضرورية لتجنّب العودة إلى القمع والاستبداد وانتهاك حقوق الإنسان وسوء التصرف في المال

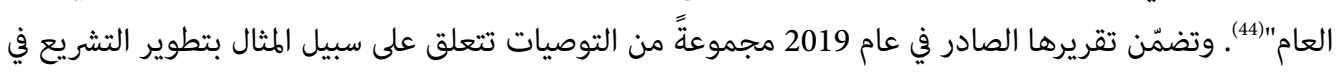
المجال العقاري، وبإرساء مناخ من الشفافية في المجال المالي والبنكي والجبائي، وحماية الثروات الطبيعية (45).

\section{2. دور الإصلاحات السياسية في الوقاية من الفساد}

يشير عدد من البحوث والدراسات إلى أنه من غير الممكن تصوّر سياسات لكافحة الفساد في سياق غير ديمقراطي (46).

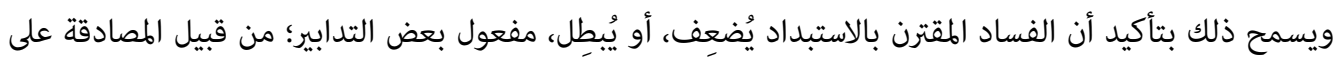

40

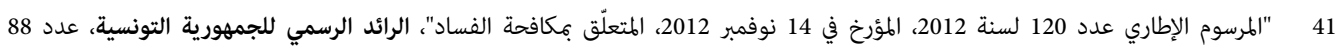
(18 تشرين الثاني/ نوفمبر الطاري عدد 2011)، ص 2746.

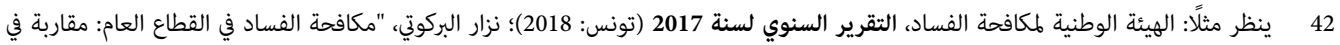
تطبيق قواعد الحوكمة الرشيدة"، أطروحة دكتوراه في القانون العام، جامعة تونس المنار، كلية الحقوق والعلوم السياسية، تونس، لنئ،

43 "Un exemple étranger d'agence anticorruption: l'instance nationale de lutte contre la corruption de Tunisie," in: Service central de prévention de la corruption, Rapport pour l'année 2013 au premier ministre et au garde des sceaux, ministre de la justice (Paris: Direction de l'information légale et administrative, 2014), p. 279, accessed on 14/6/2020, at: https://bit.ly/2YzfmzH

يكن الاطلاع على صلاحيات الهيئة الماليزية مكافحة الفساد، في: https:/bit.ly/34AVgXb

44

45

46 Michael Johnston, "Corruption et démocratie: Menaces pour le développement, possibilités de réforme," Tiers-Monde, vol. 41, no. 161 (2000), p. 116; Yves Mény et al. (eds.), Démocratie et corruption en Europe (Paris: La découverte, 1995). 
اتفاقية دولية لككافحة الفساد، أو سَنّ تشريعات وطنية لدعم الشفافية في الحياة العامة، مثل قوانين التبليغ عن الفساد أو التصريح بالكاسب والممتلكات. وتبعًا لذلك، تصير التدابير التقنية غير ذات أثر في الواقع إذا لم ترافقها ولم تعاضدها تدابير جوهرية تسعى لدفع التنمية السياسية ودعم الديمقراطية على وجه الخصوص. تعتبر الديمقراطية مثلما ضبط مفهومها فقيه القانون الدستوري، جورج فيدال، إطارًا لسلطة تستمد شرعيتها من الشعب، ولتعدد الآراء وتقسيم السلطة وضمان الحقوق والحريات ودولة يخضع فيها الجميع للقانون (47). يساعد مفهوم الديمقراطية على تلمّس الدور الذي يمكن أن تقوم به في مكافحة الفساد؛ إذ تعمل مطهّرًا للحياة السياسية من رجال السياسة الذين تعلق بهم شُبهات فساد، كما أنها تعطي فرصة، أو تزرع الأمل لدى الناخبين، بشأن إمكان غربلة السياسيين والتخلص من الفاسدين عن طريق عدم التصويت لهم في المواعيد الانتخابية الدورية وليس عن

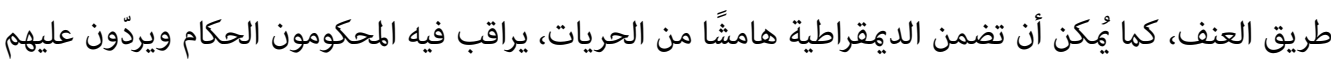

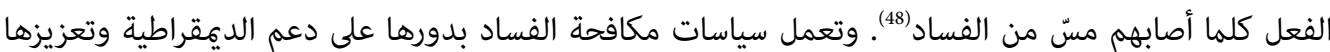
من منطلق أنها تحمي نزاهة العمليات الانتخابية وحريتها، كما تحدّ من سيطرة أقلية من أصحاب النفوذ المالي على الانتخابات، وتمنع تسرّبهم أو تحكّمهم المباشر في سلطة القرار من أجل التأثير في السياسات العمومية، خدمةً لمصالحهم الاقتصادية والسياسية الخاصة (49).

قدّمت تونس كمناسبة الانتخابات الرئاسية السابقة لأوانها، التي جرت في أواخر عام 2019، مثالًا للكيفية التي تعمل بها الآليات الديمقراطية في مكافحة الفساد، فقد وضعت هذه الانتخابات في دورها الثاني مرشََّحَن، فاز أحدهما

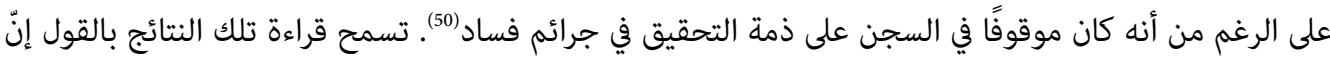

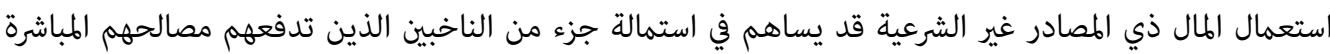
إلى التصويت لمرشحين اختلط عندهم المال الآتي من الفساد بالهال الآتي من مصدر شرعي. غير أن نتائج الدور الثاني

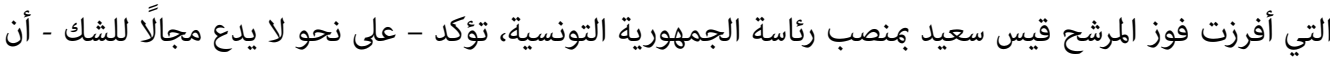
غالبية الناخبين استنفرت في نهاية المطاف للحيلولة دون وصول مرشح تحوم حوله شبهات فساد على حساب مرشح مشهود له بالنزاهة.

يطرح في إطار علاقة الديمقراطية بكافحة الفساد إشكال واقعي مرتبط بالقول بتفاقم الفساد أو استقراره في فترات الانتقال الديمقراطي؛ ففي تونس تذهب بعض إمؤشرات والدراسات إلى انفجار الفساد واستشرائه في المراحل التي

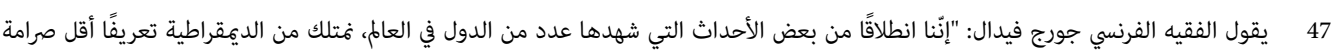

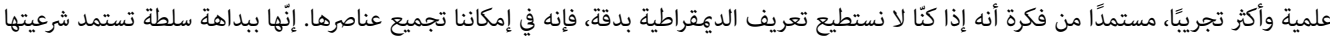

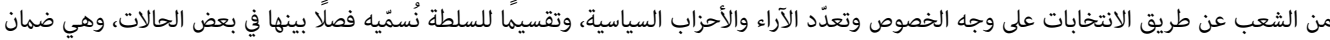

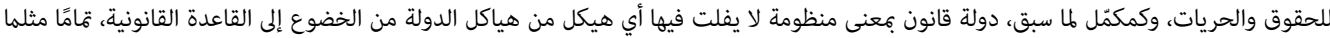

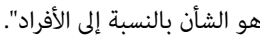
Georges Vedel, "Introduction à la justice constitutionnelle," in: La justice constitutionnelle, Table ronde de Tunis, 13-16 Octobre 1993 (Tunis: CERP, 1995), p. 21.

48 Philippe Bezes \& Pierre Lascoumes, "Percevoir et juger la corruption politique. Enjeux et usages des enquêtes sur les représentations des atteintes à la probité," Revue Française de Science Politique, vol. 55, no. 5-6 (2005), p. 757.

49 Ibid.

50

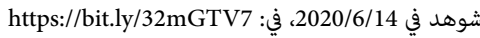


تلت الثورة، وإلى تأكيد عجز الدولة عن إيجاد الحلول الناجعة للحدّ من تفاقمه (51). يتأكد لنا ذلك من خلال تراجع

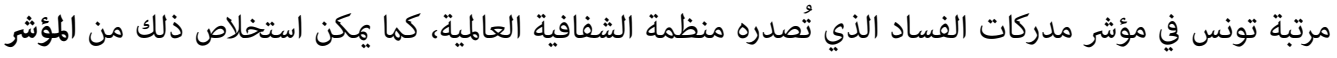

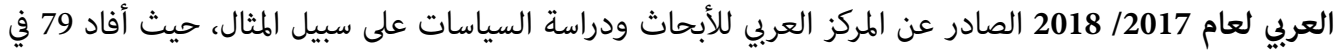
المئة من المستجيبين أن الفساد "مستشرٍ جدَّا" في تونس (52). تقتضي المنهجية العلمية تدقيق بعض التعميمات المرتبطة بتونس التي مثّلت قبل عام 2011 فوذجًا للدول التي يسيطر عليها الفساد الكبير المقترن بالاستبداد السياسي، حيث "تفشّى الفساد على امتداد 23 سنة من سوء الحكم في مئي

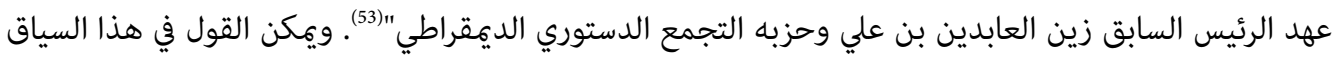
إن الثورة التي حصلت في تونس ساهمت في تخليص الدولة والمجتمع من حكم الأقلية المحتكرة للسلطة والثروة؛

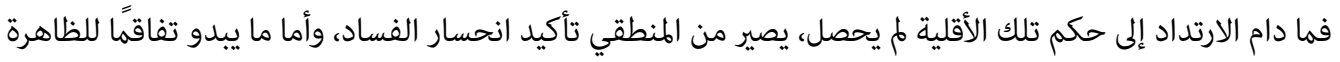

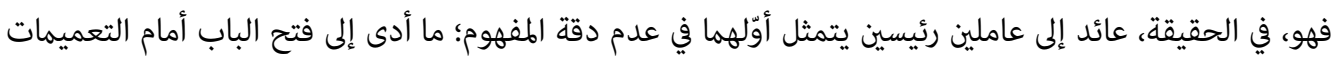

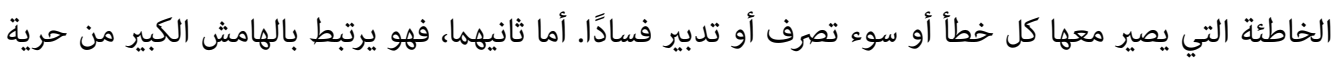

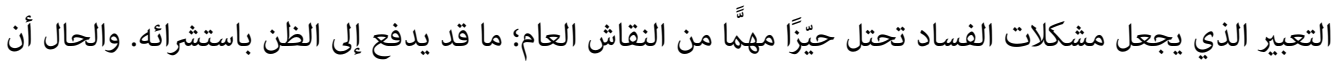

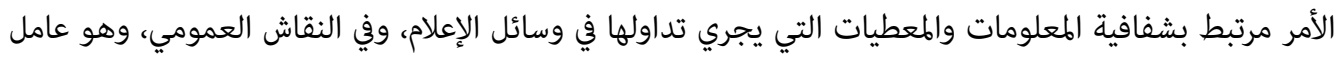
مساعد، في جوهره، على انكشاف الفساد بحجمه الكبير، أو الصغير، وتقلّصه.

يكمن حصر الإشكال، بصفة عامة، في الصعوبات التي تعترض الدولة في مجال مكافحة الفساد خلال فترات الانتقال

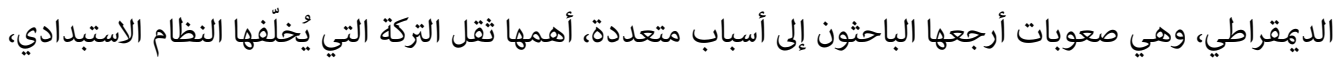

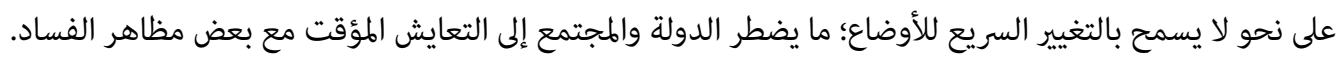

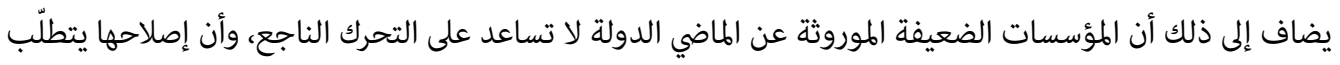

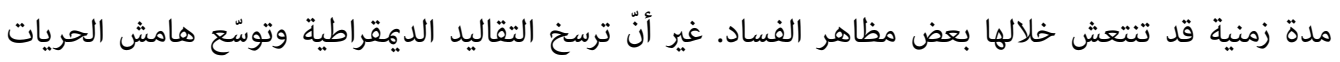

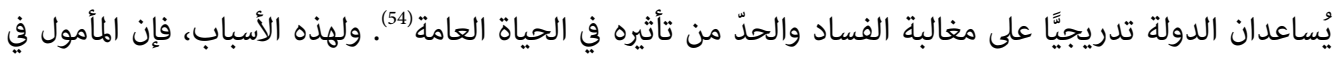

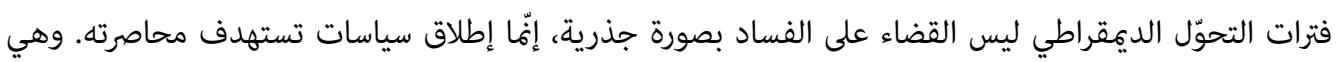

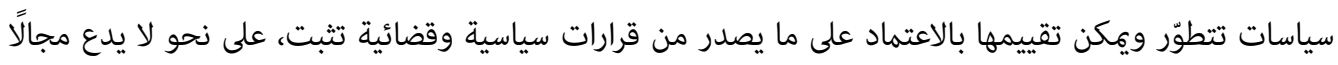
للشك، أن الدولة متحفّزة ضد الفساد، وأنها لا تنتقي ولا تتهاون في الحسم مع فاهي فاهرة يعتبرها بعضهم "المحاولة الأكثر جدّية للإطاحة بدولة القانون والمجتمع الديمقراطي" (55).

51

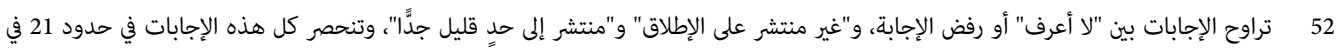

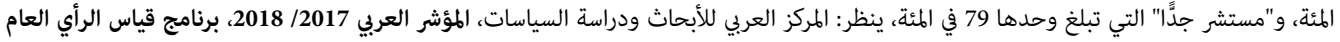

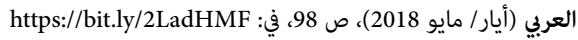
53 مركز العمليات الانتقالية الديمقراطية، المؤسسة الدولية للديمقراطية والانتخابات، برنامج الأمم المتحدة الإفائي، مكافحة الفساد - أطر دستورية لمنطقة الشرق الأوسط وشمال أفريقيا، 2014، ص 14. 54

Steven Heydemann, "Après le séisme. Gouvernement économique et politique de masse dans le monde arabe," Critique internationale, vol. 4, no. 61 (2013), p. 69.

55 Mireille Delmas-Marty \& Stéfano Manacorda, "La corruption, un défi pour l'État de droit et la société démocratique," Revue de science criminelle, no. 3 (1997), p. 69. 
تقتضي الوقاية من الفساد، بواسطة إصلاحات ذات صبغة سياسية، وجود إرادة سياسية تراعي اختلاف الأولويات المطروحة من دولة إلى أخرى؛ وهو ما يمكن تبيّنه من خلال المقارنة بين الحالة التونسية والحالة المصرية على سبيل المثال. ففي تونس، مثّل انتهاك حقوق الإنسان وغياب الحريات الأساسية عاملين مهمين في الانحراف بالنظام الرئاسي إلى نظام "رئاسوي"، استفرد فيه رئيس الدولة الأسبق بن علي (1987-2011) بالسلطة التنفيذية وطوّع السلطة التشريعية وأجهزة الدولة لمالحه، على نحو مل يدع مجالًا لأي توازن بين السلطات قادر على الى الحدّ من نفوذه وردعه

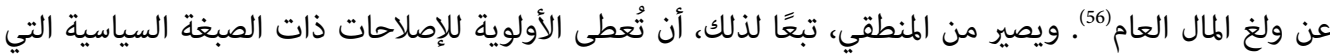

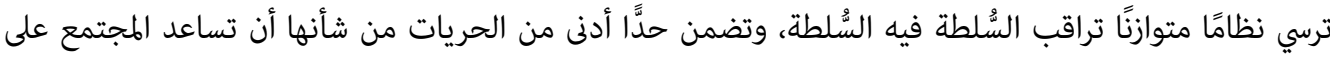

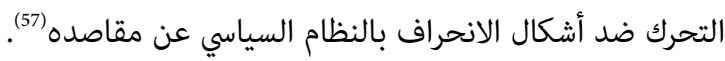

أما في مصر، فيعتبر تدخل المؤسسة العسكرية في جميع مناحي الحياة السياسية والاقتصادية عقبةً تحول دون إرساء دولة ديمقراطية تُحرّر إرادة الشعب، وتعمل من خلالها أجهزة الدولة على رفع التحديات التهي التياهي تعرقل التنمية (58). ولا تبدو هناك قيمة في ظل هذا الوضع للنصوص القانونية المتعلقة بمكافحة الفساد، إذا مل تتجه الإرادة السياسية

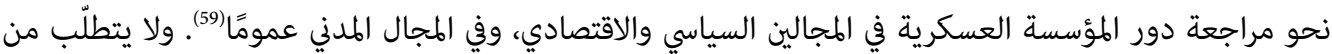

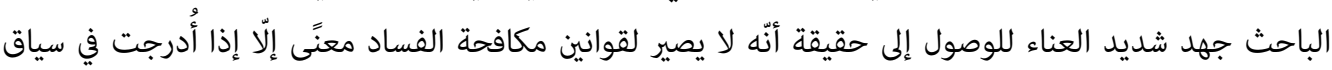
ديمقراطي تحرري تُضبط فيه حدود حركة الفاعلين السياسيين والاقتصاديين، ويكثر فيه المتربصون بالفساد، ويقل

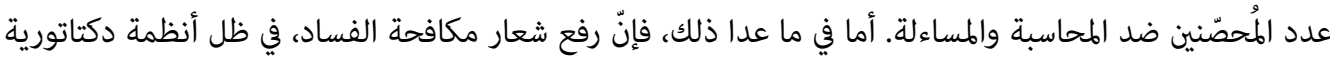

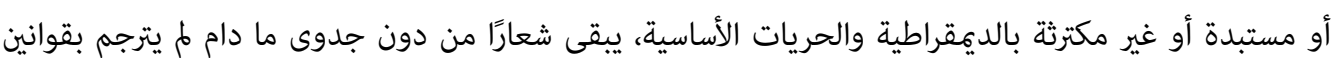

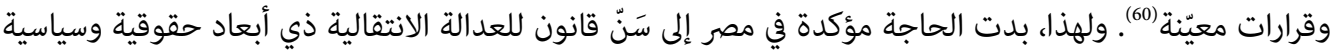

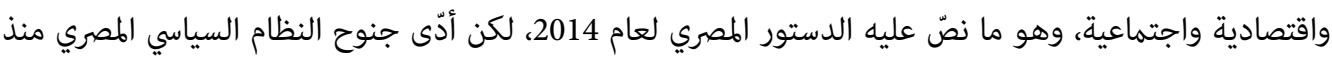
عام 2013 نحو الانغلاق، إلى مراجعة هذا وهونه مالخيار (61).

نخلص، مما سبق، إلى أن ربط مكافحة الفساد بفكرة الديمقراطية وفكرة دولة القانون عامل داعم لجهود مكافحة

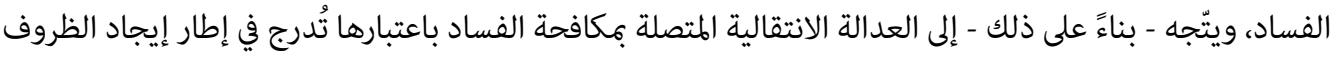
المساعدة على دعم الديمقراطية ودولة القانون ومكافحة الفساد. ومن المؤكد، في هذا الصدد، أنّ الترابط بين تصفية

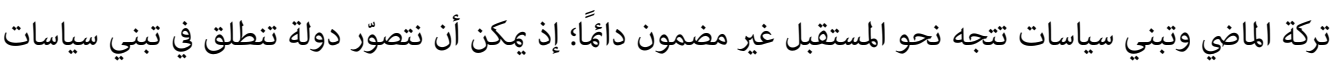

56 لطفي طرشونة، "منظومة التسلّط في النظام السياسي التونسي قبل ثورة 14 جانفي 2011"، الهجلة التونسية للدراسات القانونية والسياسية، العدد 1 . 7 (2012) 57 57 المهدي مبروك، "الثورة التونسية الملهمة"، العربي الجديد، 2019/1/30. 58 عزمي بشارة، "الجيش والحكم عربيًا: إشكاليات نظرية"، سياسات عربية، العدد 22 (أيلول/ سبتمبر 2016)، ص 7؛ زولتان باراني، "القوات الطسلحة

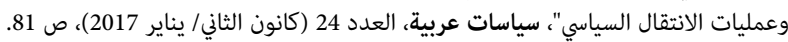

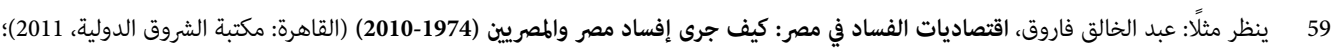

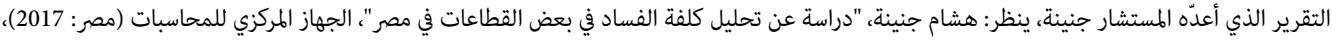
شوهد في 2020/6/14، في: وطُ وحُكم لاحقًا على المستشار جنينة بالسجن نتيجة تصريحات إعلامية بشأن الفساد في مصر. 60 م ينظر مثلاً: مصطفى العزب، "الآثار الاجتهاعية للقرارات الاقتصادية في مصر"، تقارير، مركز الجزيرة للدراسات، 22 تشرين الأول/ أكتوبر 2018؛ عبده موسى، "تركة مبارك لا تزال تحكم مصر: إلى أي وجهة تأخذنا الانتخابات البركانية المقبلة؟"، سياسات عربية، العدد 13 (آذار/ مارس 2015)، ص 49. ht 
مكافحة الفساد وتنفيذها من دون الالتفات إلى الماضي، لكن يكتسي الربط أهميةً بالغة بالنسبة إلى الدول التي تسعى لترسيخ الديمقراطية؛ نظرًا إلى ثقل التركة وخطر الارتداد نحو الاستبداد والفساد الماثل في هذه المراحل الصعبة إنبة التي لم تترسخ فيها قواعد مكافحة الفساد ومبادئها.

\section{خاتمة}

يسود في تونس انطباع بشأن تعثر جهود مكافحة الفساد، بما في ذلك الجهود التي انصهرت في مسار العدالة الانتقالية، انطلاقًا من أن التدابير الزجرية لم تَطل جميع المتورطين المحتملين في الفساد؛ ما يدفع إلى النظر إلى التدابير الوقائية بوصفها تكديسًا للنصوص القانونية غير ذات الجدوى، وتأسيسًا لهياكل خاوية غير قادرة على النهوض بهماتها المتصلة بمكافحة الفساد. يؤكد لنا ذلك أن الثقة التي تبحث عنها الدولة باستمرار، في ما تتخذه من إجراءات ضدّ الجّاء الفساد، ترتبط إلى حدًّ ما بقدرتها على التعامل مع الفساد الذي استشرى سابقًا. ملم تشذّ العدالة الانتقالية المرتبطة بكافحة الفساد عن الانطباع المبني على عدم نجاحها في تحقيق أهم أهدافها، غير أن ذلك يجب ألا يؤدي إلى إعلان الفشل النهائي لهذا المسار؛ نظرًا إلى تواصل مسار الانتقال الديمقراطي في تونس الذي يعتبر المجال الوحيد الممكن لتطهير الحياة العامة والحياة السياسية من الفساد.

يتيح ترسيخ التجربة الديمراطية في تونس فرصة أخرى لععالجة أفعال الفساد التي ارتكبت قبل قيام الثورة، لكن يبقى النجاح في تحقيق هذه الغاية مرتبطًا بشرط جوهري يتمثل في إعادة قراءة الأسس النظرية التي تقوم عليها العدالة الانتقالية، على نحو يؤمن المرور من سياق الحلول الثورية إلى سياق الحلول الإصلاحية. من البديهي أن تقدّم

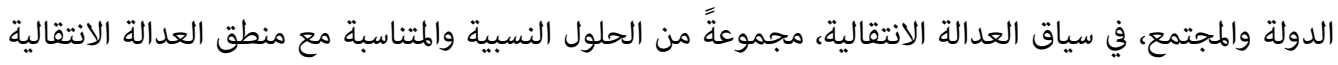

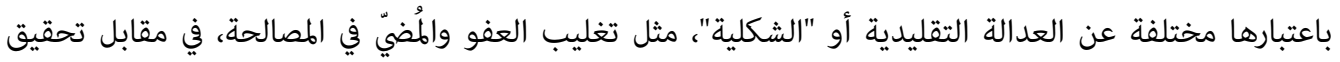
مكاسب مستقبلية متعددة، مثل استرجاع بعض الأموال المنهوبة والُُضيّ في تحقيق العدالة الاجتماعية والتنمية الاقتصادية، وخاصةً تأمين الانتقال نحو الديمقراطية.

كان لزامًا على الدولة السعي لتحقيق أهداف العدالة الانتقالية من كشف حقائق ومحاسبة ومصالحة، وهو ما مل يحصل؛ ولذلك تأرجحت العدالة الانتقالية المتصلة بالفساد بين متطلّبات العدالة الانتقالية المرنة ومتطلّبات العدالة الشكلية الصارمة، وخصوصًا في ما يتعلق بالمصالحة الاقتصادية التي تعتبر روح العدالة الانتقالية. وساهم عدم إنجاز المصالحة الاقتصادية في استمرار تداول حجم من الأموال في الحياة العامة مصدرها الفساد؛ ذلك أن بقاء رجال الأعمال المتورطين في الفساد تحت طائلة الابتزاز السياسي يدفعهم إلى البحث عن الحماية والحصانة عن طريق تمويل السياسيين الذين يحققون لهم تلك الغاية.

بناءً على ما سبق، يمكن تأكيد أن إعادة إطلاق جهود المصالحة الاقتصادية أضحت اليوم ضرورة لتطهير الحياة السياسية من المال الفاسد؛ ما من شأنه أن يدعم مسار الانتقال الديمقراطي. ويتطلّب ذلك استكمال مسار العدالة الانتقالية على نحو مطابق لقواعد قانون العدالة الانتقالية ومبادئ الدستور، وبطريقة تُحيّد الاعتبارات السياسية الظرفية. 
في مقابل ذلك، تبرز أهمية الدولة الديمقراطية في كونها الإطار الأنسب لإيجاد بيئة طاردة للفساد؛ فالدولة الديمقراطية ليست دولة خالية من الفساد، لكن ترسّخ الآليات الديمقراطية الإجرائية واتساع نطاق الحريات والفصل الواضح بين

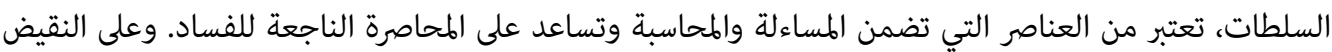
من ذلك، يؤدي الاستبداد وغياب الديمقراطية إلى التغييرات العنيفة التي لا تضمن انتقالًا ديمقراطيًا ولا مكافحة فساد. لتهن

\section{المراجع}

العربية

أبو الدهب، نهى. "سياسات العدالة الانتقالية في السياقات السلطوية: الحالة المصرية". موجز السياسة، مركز

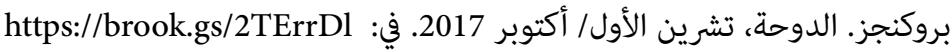

باراني، زولتان. "القوات المسلحة وعمليات الانتقال السياسي". سياسات عربية. العدد 24 (كانون الثاني/ يناير 2017). البركوتي، نزار. "مكافحة الفساد في القطاع العام: مقاربة في تطبيق قواعد الحوكمة الرشيدة". أطروحة دكتوراه في

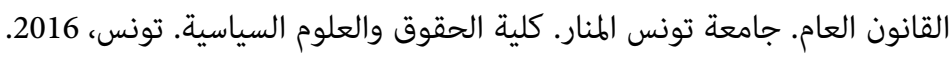

بشارة، عزمي. الثورة التونسية المجيدة: بنية ثورة وصيرورتها من خلال يومياتها. الدوحة/ بيروت: المركز العربي للأبحاث ودراسة السياسات، 2012.

"الجيش والحكم عربيًا: إشكاليات نظرية". سياسات عربية. العدد 22 (أيلول/ سبتمبر 2016).

بلكوش، الحبيب. "العدالة الانتقالية والانتقال الديمقراطي في السياق العربي". سياسات عربية. العدد 18 (كانون الثاني/ يناير 2016).

بن عاشور، عياض. تونس: ثورة في بلد الإسلام. ترجمة فتحي بن الحاج يحي. تونس: سيراس للنشر، 2018. توفيق، راوية. "هل الدولة والمجتمع مستعدان في مصر للعدالة الانتقالية والمصالحة الوطنية؟ دروس من جنوب أفريقيا". سياسات عربية. العدد 6 (كانون الثاني/ يناير 2014).

"تونس: المشهد السياسي في ضوء نتائج الانتخابات الرئاسية والتشريعية". تقدير موقف. المركز العربي للأبحاث https://bit.ly/32mGTV7 ودراسة السياسات. 2019/10/17. فئي

الجمعية العامة للأمم المتحدة. مجلس حقوق الإنسان. التقرير النهائي للجنة الاستشارية لمجلس حقوق الإنسان، بشأن موضوع

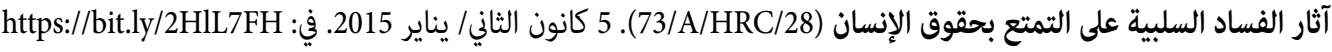
الجمهورية التونسية. الهيئة الوطنية لكافحة الفساد. التقرير السنوي لسنة 2017. تونس: 2018. . تقرير اللجنة الوطنية لتقصي الحقائق حول الرشوة والفساد. تونس: 2012. 
تقييم الانتقال الديمقراطي في تونس بعد 3 سنوات. تونس: مركز الكواكبي للتحولات الديمقراطية، مؤسسة كونراد https://bit.ly/3fjUjrO أدناور، 2014. في

الجمهورية التونسية. هيئة الحقيقة والكرامة. التقرير الختامي الشامل. تونس: كانون الأول/ ديسمبر 2018. في: https://bit.ly/2RMXk9G

الرديسي، حمادي. "تونس بين تدعيم الديمقراطية وتفكك الدولة". سياسات عربية. العدد 18 (كانون الثاني/ يناير 2016). السوسي، أحمد وآخرون. في الانتقال الديمقراطي والإصلاح الدستوري في البلدان المغاربية. تونس: مجمّع الأطرش، 2015. صديقي، العربي. "التنمية الإقليمية في تونس: تداعيات التهميش المركّب". موجز السياسة. مركز بروكنجز. الدوحة،

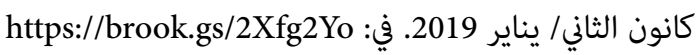

طرشونة، لطفي. "منظومة التسلّط في النظام السياسي التونسي قبل ثورة 14 جانفي 2011". المجلة التونسية للدراسات القانونية والسياسية. العدد 1 (2012).

عبد الرحيم، حافظ. الزبونية السياسية في العالم العربي: قراءة اجتماعية سياسية في تجربة البناء الوطني بتونس. بيروت: مركز دراسات الوحدة العربية، تمبية 2006.

عبد اللطيف، كمال. "العدالة الانتقالية والتحولات السياسية في المغرب: تجربة هيئة الإنصاف والمصالحة". سياسات عربية. العدد 5 (تشرين الثاني/ نوفمبر 2013).

العزب، مصطفى. "الآثار الاجتماعية للقرارات الاقتصادية في مصر". مركز الجزيرة للدراسات، 22 تشرين الأول/ أكتوبر 2018.

فاروق، عبد الخالق. اقتصاديات الفساد في مصر: كيف جرى إفساد مصر والمصريين (1974-2010). القاهرة: مكتبة

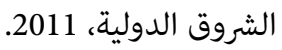

الفرشيشي، وحيد. "هل تلتزم الدولة بتنفيذ نظام العدالة الانتقالية؟". ورقة مقدمة في ملتقى علمي: الدستور التونسي على محك السياسة. جمعية البحوث في الانتقال الديمقراطي. تونس، 25-2019/1/26.

الفرشيشي، وحيد [وآخرون]. العدالة الانتقالية في تونس: غياب إستراتيجية واضحة وغلبة الارتجال. تونس: المعهد العربي لحقوق الإنسان، 2012.

ـ العدالة الانتقالية في تونس وصدر القانون! أكتوبر 2011 - ديسمبر 2013. تونس: مركز الكواكبي للتحولات الديمقراطية؛ الجمعية التونسية للدفاع عن الحريات الفردية؛ UNDP، 2014. في: فكري، مروة. "مصالحات غير مكتملة قراءة نقدية في كتاب ثورات لم تنته: اليمن وليبيا وتونس بعد الربيع العربي".

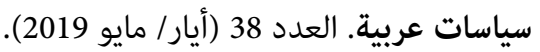


مجموعة الأزمات الدولية. الانتقال-المعظّل في تونس: فساد مالي ونعرات جهوية، تقرير الثرق الأوسط وشمال https://bit.ly/2XNXIu0 أفريقيا رقم 177. 10 أيار/ مايو

. تونس: العدالة الانتقالية ومكافحة الفساد، تقرير الشرق الأوسط وشمال أفريقيا عدد 168. بروكسال، 3 أيار/ مايو 2016. في:

مجموعة مؤلفين. أطوار التاريخ الانتقالي: مآل الثورات العربية. الدوحة/ بيروت: المركز العربي للأبحاث ودراسة السياسات، 2015.

. الثورات العربية: عسر التحوّل الديمقراطي ومآلاته. الدوحة/ بيروت: المركز العربي للأبحاث ودراسة السياسات، 2018.

المركز العربي للأبحاث ودراسة السياسات. المؤشر العربي 2017/ 2018، برنامج قياس الرأي العام العربي (أيار/مايو https://bit.ly/2LadHMF 2018) في

مركز العمليات الانتقالية الديمقراطية. المؤسسة الدولية للديمقراطية والانتخابات. برنامج الأمم المتحدة الإفائي. مكافحة الفساد- أطر دستورية لمنطقة الشرق الأوسط وشمال أفريقيا. 2014.

موسى، عبده. "تركة مبارك لا تزال تحكم مصر: إلى أي وجهة تأخذنا الانتخابات البرمانية المقبلة؟". سياسات عربية.

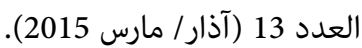

مولاي عبد الكريم، مولاي أحمد. "الأسس الفلسفية لفهوم العدالة الانتقالية مقاربة أولية". تبيّن. العدد 11 (شتاء 2015). الهيئة الوطنية لكافحة الفساد. مجموعة النصوص القانونية المتعلقة بمكافحة الفساد. ط 3. تونس: الشركة التونسية للنشر وتنمية فنون الرسم، 2019.

الأجنبية

Bezes, Philippe \& Pierre Lascoumes, "Percevoir et juger la corruption politique. Enjeux et usages des enquêtes sur les représentations des atteintes à la probité." Revue Française de Science Politique. vol. 55, no. 5-6 (2005).

De Greiff, Pablo "Analyse du Projet de loi organique relative aux procédures spéciales concernant la réconciliation dans les domaines économique et financier. Rapporteur spécial sur la promotion de la vérité, de la justice, de la réparation et des garanties de non-répétition. at: https://bit.ly/2tUKdb1 Delmas-Marty, Mireille \& Stéfano Manacorda. "La corruption, un défi pour l'État de droit et la société démocratique." Revue de science criminelle. no. 3 (1997).

Dobry, Michel. "Les voies incertaines de la transitologie: Choix stratégiques, séquences historiques, bifurcations et processus de path-dependence." Revue Française de science politique. vol. 50, no. 4-5 (2000). 
Heydemann, Steven. "Après le séisme. Gouvernement économique et politique de masse dans le monde arabe." Critique internationale. vol. 4, no. 61 (2013).

Hibou, Béatrice. La force de l'obéissance: économie politique de la répression en Tunisie. Paris: La découverte, 2006.

Janot, Philippe. "Firmes Transnationales, Corruptions, États." Annuaire Français de Droit International. vol. vi (2005).

Johnston, Michael. "Corruption et démocratie: Menaces pour le développement, possibilités de réforme." Tiers-Monde. vol. 41. no. 161 (2000).

La justice constitutionnelle. Table ronde de Tunis, 13-16 Octobre 1993. Tunis: CERP, 1995.

Loued, Mohamed Naceur et al. (eds.). Transparence financière et réformes institutionnelles. Tunisie: Faculté des sciences juridiques, économiques et de gestion de Jendouba, 2008.

Mény, Yves et al. (eds.). Corruption et démocratie en Europe. Paris: La Découverte, 1995.

Nouioua, Adnen. "La lutte contre la corruption et le droit international." Thèse de doctorat en droit public. Université de Tunis Al Manar. Faculté de droit et des sciences politiques. Tunis, 2018. Service central de prévention de la corruption. Rapport pour l'année 2013 au premier ministre et au garde des sceaux, ministre de la justice. Paris: Direction de l'information légale et administrative, 2014.

Taleb, Akila. "Les procédures de Guilty Plea: Plaidoyer pour le développement des formes de justice négociée au sein des procédures pénales modernes." Revue internationale de droit pénal. vol. 83. no. 1 (2012).

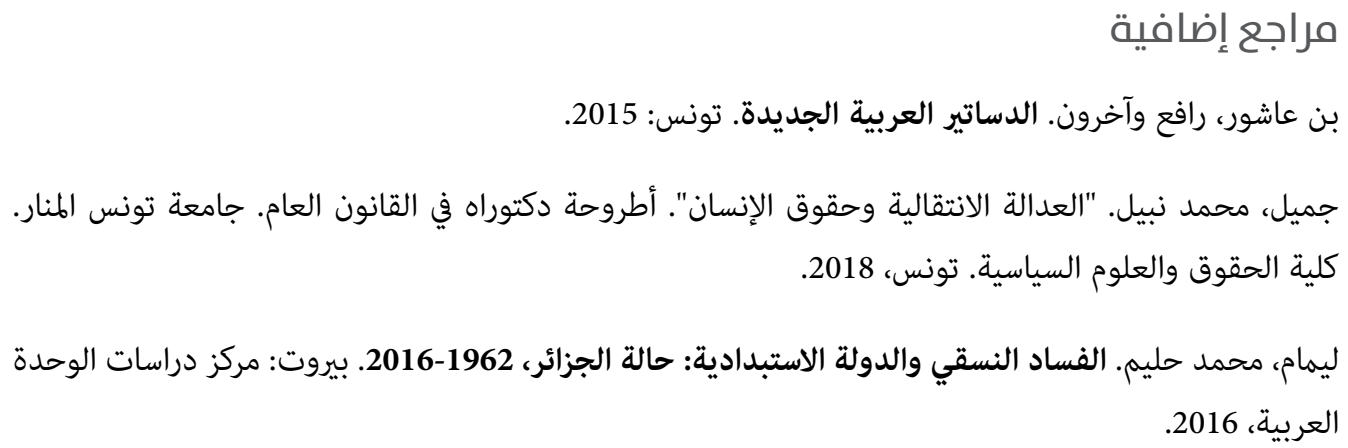

Boniface, Pascal. "La lutte contre la corruption, nouveau paradigme des relations internationales." Revue internationale et stratégique. no. 101 (2016). 